\title{
$\mathrm{DC}$ 누설 전류 검출 알고리즘을 내장한 누전 차단기 개발 Development of ELCB with Built-in Algorithm for DC Leakage Current Detection
}

\author{
주남규 - 김 남호* \\ 강원대학교 전기전자공학과
}

Nam-Kyu Joo $\cdot$ Nam-Ho Kim*

Department of Electrical and Electronic Engineering, Kangwon National University, Kangwon-do, 200-701, Korea

\section{[요 약]}

손쉬운 제어성, 운용성 등 다양한 이유로 디지털 부하가 급증하고 있고 이와 함께 부하의 소비 패턴은 직류화 되고있 다. 그러나 공급되는 전력은 교류 전원이므로 실질적으로 필요로 하는 부하의 공급 전원인 직류 전원을 만족하기 위하여 교류 전원을 다시 직류로 변환하여 사용하고 있다. 태양광, 풍력, 연료전지 등 신재생 에너지원의 경우 직류 발전을 하 는 발전원으로 교류로 변환을 통해 계통에 유입되고 다시 직류로 변환되어 부하에 공급하게 되는 다단 변환을 하게 되 어 손실은 지속적으로 증가하게 된다. 에너지원의 효율적인 사용을 위한 직류 기반의 배전 시스템이 필요로 하나, 부하 뿐만 아니라 보호 기능을 구현하기 위한 직류 배선용 누전 차단기의 개발이 필요하다. 이에 본 연구에서는 직류 누설 전 류에 대한 검출 알고리즘을 구현하고, 이를 위하여 센서에 대한 성능을 검증하고 이를 활용하여 직류를 기반으로 하는 누전 차단기에 적용함으로써 직류 배전 시스템 운용에 있어 보호가 가능할 것으로 기대된다.

\section{[Abstract]}

Digital load is increasing suddenly for various reasons, such as easy control and management. Accordingly, a consumption pattern of load is becoming DC. However, the power supply is supplied by AC power. The load power supply substantially needs DC power. AC power has to be converted to DC power. Renewable energy sources like solar, wind, fuel cells are DC power generation, but the transfer needs to through by AC power, thus DC power has to be converted to AC power. Resultantly, a multi-stage conversion loss is constantly increasing. The power distribution system of DC-based is required for effective use of these energy sources. This requires a DC load, as well as is necessary to develop DC ELCB which are able to detect DC leakage current for implementing protection. In this study, it realize detection algorithm about DC leakage current to verify the performance of the sensor and apply it to the ELCB which is based on DC. Therefore, it is expected to protect operating of DC power distribution system.

Key word : Distribution, Digital load, Solar Power generation, ELCB, Protection.

\section{http://dx.doi.org/10.12673/jant.2014.18.2.165}



Received 31 March 2014; Revised 26 April 2014

Accepted (Publication) 22 April 2014(30 April 2014)

*Corresponding Author; Nam-Ho Kim

Tel: +82-31-329-5294

E-mail: nhk@kangwon.ac.kr 


\section{I. 서 론}

인류 문명의 발전과 함께 기술의 발전은 산업사회에서 컴퓨터를 대표로 하는 정보화 사회로 변환되고 있고, $\mathrm{TV}$, 세 탁기, 시스템 에어컨 등 다양한 전자 기기와 LED 조명 등과 같은 조명 시설이 삶의 편의성에 있어 매우 중요한 부분이 되어 사용되고 있다. 그러나 이러한 기기들은 직류 기반의 기기들이기 때문에 교류 기반의 전력 설비에서 공급을 받아 직류로 변환하여야 하므로 어쩔 수 없는 변환 손실이 발생 하고 있다. 또한 이러한 교류를 발생시키는 발전 에너지원 으로 화석연료를 사용하고 있으나, 우리나라의 경우 $100 \%$ 수입에 의존하고 있어, 2011년도 에너지 수입액이 1,695억 불로 국내 주력 수출 품목인 반도체, 자동차, 선박의 총합 수 출액인 1,495 억불을 상회하고 있어 국가, 사회적으로 매우 큰 손실을 발생하고 있다.

이러한 이유로 신재생 에너지의 발전 비율을 높일 필요 성이 증대되고 있으나, 신재생에너지를 대표하는 태양광, 연료전지, 풍력 등은 직류 발전을 하기 때문에 직류를 교류 로 교류를 다시 직류로 변환하는 다변환 시스템이고 그에 따른 변환 과정에서 발생되는 손실은 $30 \%$ 에 달한다.

손실을 저감하기위해 인터넷데이터센터에서는 직류배 전을 통해 교류 배전 시스템과 비교해본 결과 최소 $13.2 \%$ 에 서 최대 $25 \%$ 까지 매우 높은 효율을 향상할 수 있었다 [1].

에너지의 최적화사용을 위해서 공항과 같은 다중이용시 설의 경우 조명을 $\mathrm{LED}$ 등으로 변환을 통하여 조명에서도 매 우 높은 효율 향상을 가지고 올 수 있다.

그러나 효율성을 위한 직류 배전을 위해서는 부하 설비 의 직류화, 직류에 대한 보호기기들이 안정적으로 조합이 이루어져야 편리하고, 효율적이며, 안전하게 사용을 할 수 있다[2].

하지만 직류는 교류와 달리 전류가 일정하게 흐르기 때 문에 고장전류가 발생하게 되면 안정적으로 차단을 하기가 어려워 이에 대한 기술 개발이 필요하다 [3],[4].

\section{II. 본 론}

\section{2-1 전류에 따른 인체의 영향}

감전사고의 발생과정은 노출된 충전부에 인체 접촉하여 발생하는 경우, 누전된 전기기계기구의 금속제 외함에 인 체가 접촉하여 발생하는 경우가 가장 일반적이다. 감전에 의한 인체 영향에 대하여 IEC 60947-1 (인체와 가축에 대한 전류의 영향. 제 1 부 일반적인 양상 2007 에서 규정하고 있으 며, 인체 위험은 주로 통전 경로 통전전류의 크기와 시간에 따라 좌우된다. 전류와 전압사이의 관계는 인체 임피던스 가 접촉전압 (접촉 전류로 표시되는 인체를 통과하는 전류 와 인체 임피던스의 곱)에 따라 달라지므로 선형적이지 않
다. 인체 임피던스는 피부, 혈액, 근육 등 인체 여러 부분에 있어, 전류에 대한 저항성분과 캐패시턴스 성분으로 구성 된 임피던스로 나타난다. 인체 내부 임피던스는 대부분 저 항성분만을 고려할 수 있으며, 피부임피던스는 저항성분과 캐패시턴스의 회로망으로 해석할 수 있다.

높은 접촉전압에서 피부 임피던스는 상당히 많이 감소하 며 피부조직이 파열될 때에는 무시할 정도로 되고, 피부임 피던스는 주파수가 증가될수록 감소하게 된다.

그림 1 은 맥동이 없는 직류에서의 인체통전전류의 크기 와 통전시간에 따른 인체의 반응을 나타낸 그래프이다.

$\mathrm{DC}-1$ 은 $2 \mathrm{~mA}$ (곡선 a)까지의 영역으로 전류의 흐름, 차단 또는 갑작스런 전류 방향의 전환 시 약간의 따끔한 감각을 느낀다. DC-2는 곡선 $\mathrm{a}$ 에서 곡선 $\mathrm{b}$ 사이의 영역으로 전류의 인가, 차단 또는 갑작스런 전류 흐름의 방향이 바뀔 때 비 자 의적인 근육의 수축이 일어날 수 있으나, 일반적으로 전기 생리적인 현상으로 해롭지 않은 영역이다.

$\mathrm{DC}-3$ 은 곡선 b에서 곡선 $\mathrm{c} 1$ 사이의 영역으로 강한 비자의 적인 반응과 전류의 크기 및 시간이 증가함에 따라 심장의 회복 가능한 기능 장애 및 박동의 전도가 일어 날 수 있다. 일 반적으로 신체 기관의 손상은 예측되지 않는 범위이다. DC-4 영역은 심장 마비, 호흡정지 및 화상 또는 다른 세포의 손상과 같은 병리 생리학적인 영향을 일으킬 수 있으며, 전 류의 크기 및 시간이 증가함에 따라 심실 세동의 가능성이 커지게 된다. 그림 1 에서와 같이 직류 전원의 경우 인체 생 리학적으로 안전한 전류 범위는 DC-1, DC-2 영역이며, 연속 적인 통전에도 안전한 전류의 크기는 약 $26 \mathrm{~mA}$ 까지 임을 알 수 있다.[5]

또한 $50 \mathrm{mS}$ 이내 누설 전류의 해제 시 $100 \mathrm{~mA}$ 까지 인체 안 전영역이므로 빠른 원인 제거에 따라 인체 안정성이 매우 증가됨을 알 수 있다. 그러나 이 값은 실제 사고시의 인체의 조건 및 접촉 조건 접촉 시간 등에 따라 부상이나사망 등 다 른 결과를 가져올 수 있다.

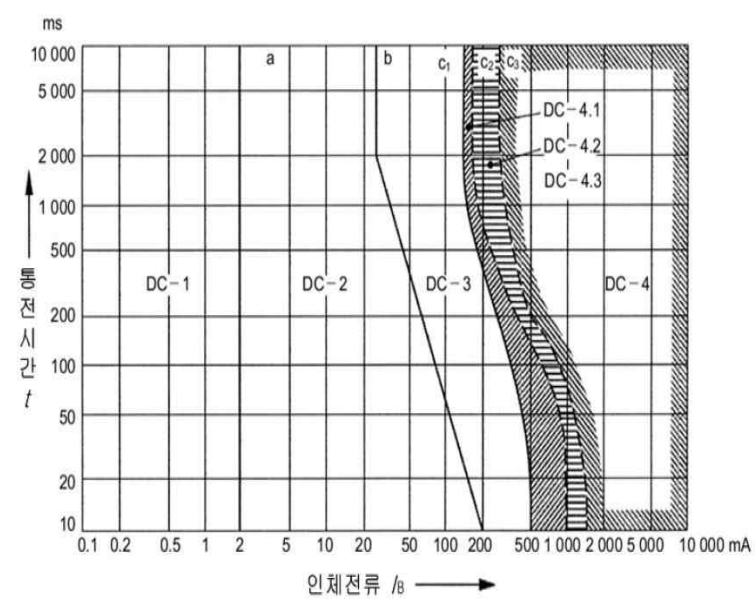

그림 1. 인체 전류와 통전시간에 다른 영향(직류)

Fig. 1. The impact of current and energizing time in human(dc). 


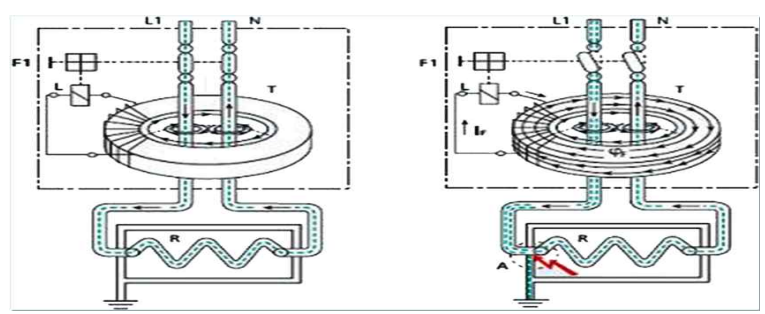

그림 2. 누전 차단기의 누설전류 검출 원리

Fig. 2. Leakage current detection principle of ELCB.



그림 3. 누전 차단기의 내부 구성도

Fig. 3. Inner part figure of ELCB.

\section{2-2 DC 누전 차단기의 개요}

그림 2는 누전 차단기의 동작 원리를 설명한 그림으로 회 로가 정상적으로 동작하고 있을 경우 좌측 그림처럼 영상 변류기(ZCT)를 통과하는 부하 전류의 벡터합은 0 가 되기 때문에 ZCT 2차측으로 전류가 유기 되지 않으나, 고장 및 사 고에 의해 누설 전류가 발생하게 되면 그림 2 의 우측처럼 $\mathrm{ZCT}$ 를 통과하는 전류의 벡터합이 평형을 잃어 0 이 되지 않 는다.

그림 3은 누전 차단기의 내부 구성으로 누설 검출 장치는 $\mathrm{ZCT}$ 와 $\mathrm{SCR}$ 을 포함하는 누전 검출 $\mathrm{PCB}$ 로 구성되어 있으며, 2 차측에 전류가 유기가 되면 $\mathrm{ZCT}$ 출력에서 전압으로 변환 되어 누설전류의 크기를 측정하게 되며, 일정치 이상의 누 설전류가 검출되면, $\mathrm{SCR}$ 신호를 출력하고, 트립코일을 동 작시켜 누설전류를 차단하게 하는 원리이며 누전 발생 여부 는 누전 표시 버튼에 의해 과부하 동작, 누전 동작에 대한 알 림기능을 구현한다.

하지만 직류배전에서는 유기 전압이 0 이 되기 때문에 평 상시에 누설전류 값에 관계없이 일정 전류 이상의 변화가 있어야 누전 차단기가 동작하게 된다.
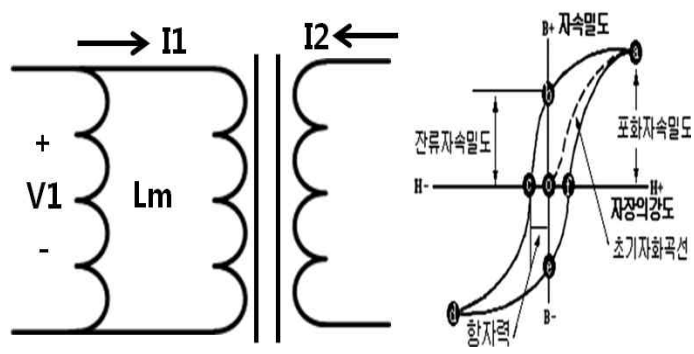

그림 4. ZCT 등가모델

Fig. 4. Equivalent model of ZCT.
그림 4에서 나타난 바와 같이 누설 전류 검출을 위한 영상 변류기 등가모델을 보면 영상변류기에 유기되는 전압은 다 음과 같다.

$$
V_{1}=L_{m} \frac{d I_{1}}{d t}
$$

또한 직류 누설전류는 영상변류기의 포화문제를 일으키 게 되고, magnetic core에 흐르는 전류가 클수록 기울기가 감 소한다. B-H curve의 순간 변화율은 유전율을 의미하기 때 문에 식 2에 의해 $\mathrm{Lm}$ 값이 감소하게 된다.

$$
L_{m}=n^{2} \frac{\mu A_{C}}{l_{m}}
$$

식 (1)에 의해 $\mathrm{Lm}$ 이 작으면 영상변류기 2차단에 일정 크 기의 전압을 유기하게 하는 전류 변화량이 커지는 것을 알 수 있다. 따라서 직류 배전에서 누설전류를 검출하기 위해 서는 직류 전류를 정확하게 검출할 수 있는 센싱 방법이 매 우 중요하다

본 논문에서는 이러한 문제를 해결하기 위하여 직류용 hall CT를 사용하여 누설 전류를 검출하며, 사용된 센서는 자기 회로의 포화 상태를 검출하는 원리로 정확도가 매우 높아 직류 및 교류 전류 검출에 널리 사용되고 있다.

\section{2-2 DC 누전 차단기 개발}

그림 5 는 개발한 $\mathrm{DC}$ 누전 차단기의 내부 구성으로 아크 소호부, 트립메카니즘, 트립 코일, O.D.P, 누설전류 감지센 서, 누설전류 검출 및 동작 $\mathrm{PCB}$ 로 구성되며, 누전 센서 입력 전압 $\mathrm{DC} 5 \mathrm{~V}$ 전원은 개발된 $\mathrm{PCB}$ 에서 공급하여 센서의 전원 으로 공급한다.



그림 5. 개발 제품의 구성 및 신호 흐름도

Fig. 5. Development of product configuration and signal flow. 


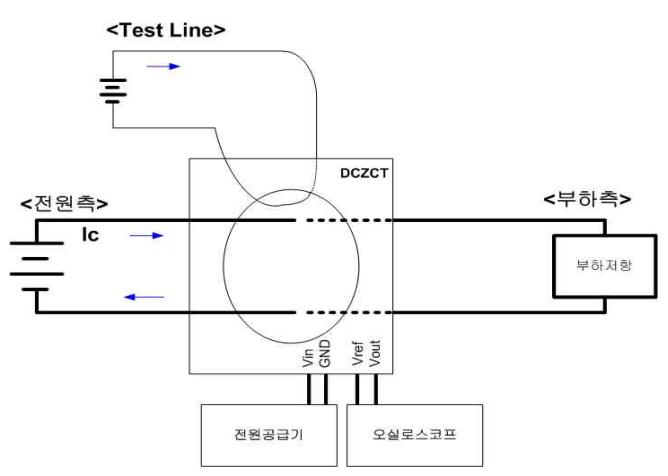

그림 6. 센서 출력 특성 시험 구성도

Fig. 6. Configuration of the sensor output characteristics test.



그림 7. 센서 출력 특성 시험 결과

Fig. 7. Output characteristic of the sensor test results.

누설전류 변화에 따른 센서 출력의 선형성이 매우 중요 하기 때문에 회로 설계를 위해서 누전 검출 센서의 출력 성 능 시험을 그림 6과 같이 구성하여 하였으며, 그림 7은 상기 센서 시험에서의 결과로 인체 안전 전류 영역인 $200 \mathrm{~mA}$ 까 지 선형적인 증가됨을 알 수 있다.

그림 8은 개발한 누전 검출 회로도로 전원부와 센싱부, 노 이즈 필터부, 누전 판단부, 트립 신호부로 구성되며, Vref 전 압으로 $2.5 \mathrm{~V}$ 에 대하여 + , -에 대한 기준으로 전류의 극성 변 화에도 출력 안정성을 확보하였고, 누전 테스트회로 구현 을 위하여 DC $12 \mathrm{~V}$ 출력과 $\mathrm{HCT}$ 에 5 turn을 구성하여 제품 설 치 후 누전 회로 동작 여부를 확인할 수 있도록 하였다.

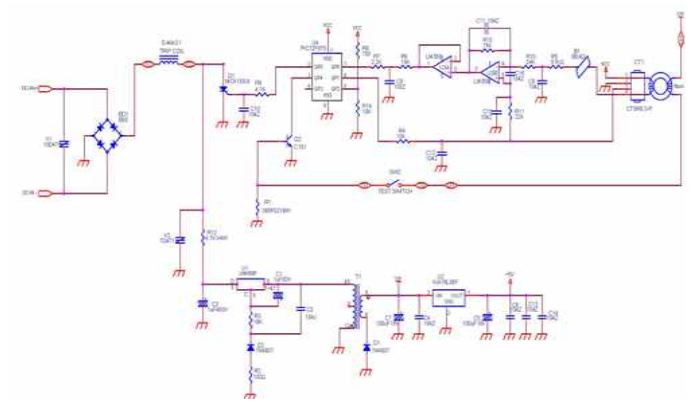

그림 8. 누전 검출 회로

Fig. 8. Leakage detection circuit.
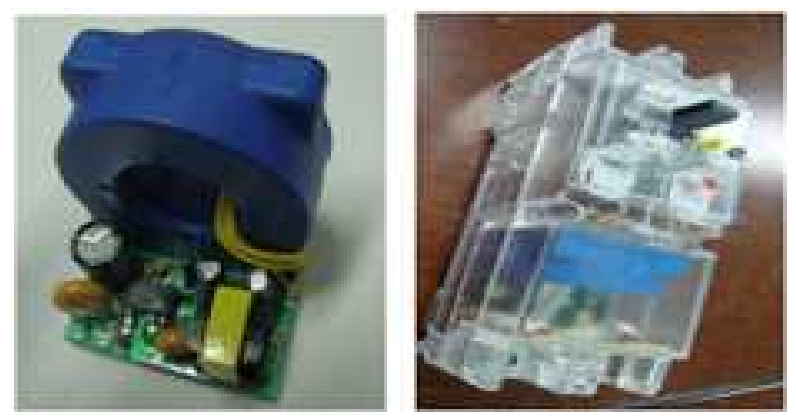

그림 9. 개발된 제품의 사진

Fig. 9 .The picture of developed DC ELCB.



그림 10. 누설전류 동작 시험

Fig. 10. Leakage current detection test.

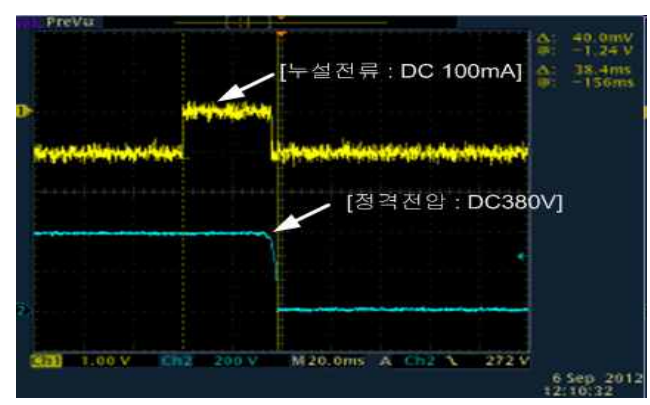

그림 11. $100 \mathrm{~mA}$ 누설 전류 동작 시험

Fig. 11. Leakage current of $100 \mathrm{~mA}$ operating test.

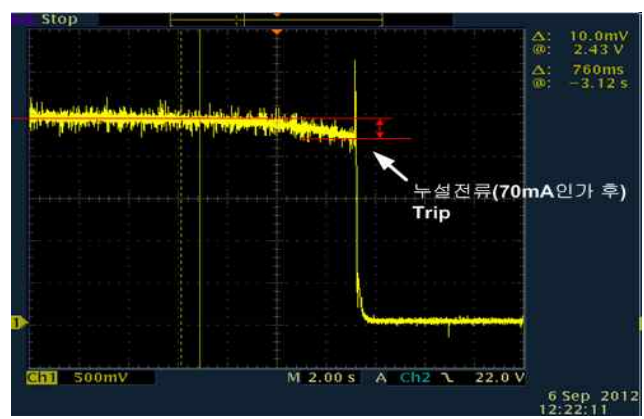

그림 12. 최소 동작 검출 성능 시험

Fig. 12. The minimum Leakage current detection test.

개발된 $\mathrm{DC}$ 누전 검출 회로는 $50 \mathrm{~mA}$ 부동작 $100 \mathrm{~mA}$ 동작 을 목표로 설계 하였으며, 최소 트립 시작 전류를 $65 \mathrm{~mA} \mathrm{75}$ 
$\mathrm{mA}$ 에 동작할 수 있도록 설계하였다.

노이즈성 누설전류에 대한 오작동 방지를 위하여 마이크 로 프로세서 PIC 12F675를 사용하여 온도보정, 노이즈 보정 에 대하여 프로그래밍 하였다.

시험 결과 누전 검출은 $70 \mathrm{~mA}$ 누전 검출을 하였으며, 누 설 전류 $100 \mathrm{~mA}$ 에서 차단 시간은 $38 \mathrm{mS}$ 로 $100 \mathrm{~mA}$ 누설 전 류 발생 시 인체안전 영역인 $50 \mathrm{mS}$ 이내에 동작함을 확인 할 수 있었다.

\section{III. 결 론}

본 연구는 에너지의 효율성 증대와 다양한 신재생에너지 의 공급에 대한 설비의 효과적인 조합을 위한 직류 배전에 최소한의 인체안전 및 전기 화재 보호 대책인 누전 검출 및 차단에 대한 보호 알고리즘을 내장한 $\mathrm{DC}$ 누전 차단기를 최 적화 설계하여 시험하였다. 실험을 통하여 알 수 있듯이 인 체 안정영역인 DC-2 영역 안에서 누설 전류를 검출하고 동 작함을 확인할 수 있었다.

이를 바탕으로 조명 시설 및 $\mathrm{DC}$ 부하가 많은 공항설비와 같은 공공성 및 다중이 이용하는 시설에서의 최적 에너지 사용을 위한 장소에서 에너지 효율뿐만 아니라 안전까지 확 보되어 직류 배전의 확대에 보다 효과적으로 사용될 것으로 판단된다.

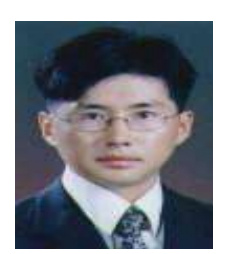

\section{주남규 (Nam-Kyu Joo)}

2002년 2월 : 강릉대학교 제어계측공학과(공학사)

2004년 2월 : 강원대학교 전기공학과 (공학석사)

2012년 2월 : 강원대학교 전기전자공학부 (박사수료)

2007년 9월 현재: (주대륙 선임연구원

※관심분야 : 차단기, 보호기기

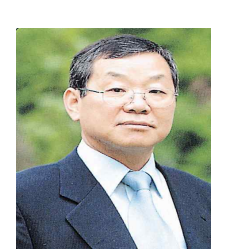

김남호 (Nam-Ho Kim)

1974년 2월 : 서울대학교 전기학과 (공학사)

1977년 2월 : 서울대학교 전기공학과 (공학석사)

1993년 2월 : 서울대학교 전기공학과 (공학박사)

1981년 2월 현재 : 강원대학교 전기전자공학부 교수

※관심분야 : 회전기기 효율화

\section{감사의 글}

본 연구는 2013년도 강원대학교 학술연구조성비로 연구로 서, 관계부처에 감사드립니다. (번호_120131172)

\section{참고문헌}

[1] S. G. Son, H. S. Mok, G. S. Park and J. Hong "A comparative study on the electric power efficiency of IDCs with AC and DC distribution systems," The Korean Institute of Illuminations and Korea Electrical Installation Engineers. Vol.22, No. 8, pp.38 44, 2008.

[2] W. G. Lee, B. H. Han, H. M. Jeong and H. S. Kim "Development of residual current detector for DC distribution system," in The Korean Institute of Power Electronics Conference, Gyeongju: Korea, pp53 54, July, 2013.

[3] G. Byeon, "A Research on the Characteristic of Fault Current of DC distribution system and AC distribution system," in Power Electronics and ECCE Asia (ICPE \& ECCE), 2011 IEEE 8th International Conference, Jeju: Korea, pp543 550, May, 2011.

[4] IEC TR 60755, "Residual current protective device dependent or independent in line voltage," 2008.

[5] H. G. Kim, D. G. Kim, G. Y. Lee, H. N. Moon and H. S. Choi "Electrical Characteristics Analysis of Power Conversion Devices of LED lighting by DC Leakage Current," in The Korean Institute of Illuminations and Korea Electrical Installation Engineers Conference, Busan: Korea, pp.2179 2180, Oct. 2010. 